\title{
AVALIAÇÃO DE FORMALDEÍdO EM AMOSTRAS DE ALISANTES CAPILARES OBTIDAS EM SALÕES DE BELEZA NO MUNICÍPIO DE ITAPACI-GO
}

\author{
EVALUATION OF FORMALDEHYDE IN SAMPLES OF HAIR STRAIGHTENERS \\ PRODUCTS OBTAINED IN BEAUTY SALONS IN THE COUNTY OF ITAPACI-GO
}

\author{
Aylla Marcela Barbosa de Oliveira \\ Discente do curso de Farmácia da Faculdade Evangélica de Ceres, Ceres-GO, Brasil. \\ ayllamarcela98@gmail.com
}

\section{Gabriele Duarte de Melo}

Discente do curso de Farmácia da Faculdade Evangélica de Ceres, Ceres-GO, Brasil. gabrieleduarte95@gmail.com

\section{Maria Juíva Marques de Faria Souza}

Mestra em Ciências Farmacêuticas pela Universidade Federal de Goiás.

Docente na Faculdade Evangélica de Ceres. juivamaria@hotmail.com

Endereço para correspondência: Av. Brasil, s/n - Setor Morada Verde, Ceres - GO, 76300000. E-mail: juivamaria@hotmail.com

RESUMO: O formaldeído é uma das substâncias que pode ser encontrado na composição de alisantes capilares. Quanto aos rótulos desses produtos devem estabelecer aos usuários a identificação de possíveis substâncias que lhes causem alergias. O objetivo foi analisar a rotulagem primária e avaliar quali-quantitativamente o formaldeído nas amostras de alisantes coletadas em salões de beleza no município de Itapaci- GO. Após coleta dos alisantes capilares nos salões de beleza de Itapaci- GO foi realizada a análise da rotulagem de acordo com a RDC $\mathrm{N}^{\circ} 7$, de 10 de fevereiro de 2015 , e a avaliação quali-quantitativa do formaldeído nas amostras segundo Guia de Controle de Qualidade de Produtos Cosméticos Agência Nacional de Vigilância Sanitária (Anvisa). Os rótulos estavam devidamente dentro das normas exigidas para embalagem primária. $\mathrm{Na}$ avaliação qualitativa, todas as amostras apresentaram-se positivas para presença de formaldeído acima de $0,01 \%$ e 83,33\% (5/6) das amostras apresentaram formaldeído acima da concentração permitida $(0,2 \%)$. Alerta-se para a 
necessidade de maior fiscalização dos alisantes pela Anvisa e campanhas educativas voltadas aos cabeleireiros e consumidores sobre seus possíveis riscos/danos à saúde relacionados a procedimentos químicos capilares com formaldeído.

Palavras-chave: Cosméticos. Progressivas Capilares. Formol. Controle de Qualidade.

\begin{abstract}
Formaldehyde is one of the substances that can be found in hair straightening products. Its function is restricted only as a preservative, having no smoothing function. The goal was to analyze the primary labels and to quali-quantitatively evaluate formaldehyde in straightening samples collected in beauty salons in the municipality of Itapaci- GO. After collection of hair straightening products in beauty salons of Itapaci- GO, the labels were analyzed according to RDC No. 7 of February 10, 2015, and the quality and quantity of the formaldehyde present in the samples was evaluated according to ANVISA Cosmetic Products Quality Control Guide. The labels were properly within the required standards for primary packaging. In the qualitative evaluation, all samples were positive for the presence of formaldehyde above $0.01 \%$ and $83.33 \%(5 / 6)$ of the samples presented formaldehyde above the allowed concentration $(0.2 \%)$. Warns of the need for closer inspection of hair straighteners products by ANVISA and educational campaigns aimed at hairdressers and consumers about their possible health risks / damages related to formaldehyde hair chemical procedures.
\end{abstract}

Keywords: Cosmetics. Progressive. Formalin. Quality control.

\title{
1. INTRODUÇÃO
}

A indústria brasileira vem se tornando promissora no mercado de cosméticos com um crescimento de $11,5 \%$ nos últimos 20 anos, procurando inovar cada vez mais em produtos de beleza para suprir a demanda de clientes que anseiam por produtos de qualidade. Entre os cosméticos mais procurados, os produtos da linha capilar têm grande representatividade no mercado brasileiro, liderando o ranking mundial de venda de alisantes capilares no ano de 2011 com 37,3 \% do mercado (ABIHPEC, 2017; AGE DO BRASIL, 2017).

Os alisantes capilares são produtos cosméticos utilizados com a finalidade de alisar, relaxar, amaciar e reduzir o volume dos cabelos, de maneira parcial. Porém, estes produtos podem causar queimaduras graves no couro cabeludo, quebra e queda dos fios, podendo levar a outras complicações mais graves como, câncer nas vias aéreas superiores por possuírem substâncias que são irritantes a pele (ASSOCIAÇÃO BRASILEIRA DE COSMETOLOGIA, 2016). 
É importante ressaltar que os cosméticos são classificados em dois níveis de risco: Grau de Risco 1 e Grau de Risco 2. O primeiro se refere aos produtos com risco mínimo para a segurança humana. Já o segundo, se enquadram os alisantes capilares que apresentam risco potencial para a segurança humana e possuem indicações específicas, cujas características exigem comprovação de segurança e/ou eficácia, bem como informações e cuidados, modo e restrições de uso. Para utilização desses produtos, é apresentado pela Anvisa uma lista de substâncias e produtos que, quando utilizados, devem segui- lá de forma a não acarretar riscos à saúde (BRASIL, 2015).

Exemplo disso é o formaldeído, que nos últimos anos no Brasil tem sido utilizado extensivamente como ativo de alisantes capilares nos procedimentos químicos nos salões de beleza com o intuito de manter um alisamento mais duradouro, em média de 1 a 4 meses, dependendo da estrutura do cabelo (FERREIRA et al., 2016; IONTA; SILVA, 2012).

Entretanto, a Anvisa publicou a Resolução Colegiada No 15, de 26 de março de 2013, a qual estabelece que o formaldeído tem seu uso limitado, podendo ser utilizado em produtos para higiene pessoal, cosméticos e perfumes apenas com ação de conservante e em produtos para endurecer as unhas, em concentrações máximas de 0,2\% e 5\%, respectivamente, sendo adicionado somente durante a fabricação. Ressalta-se que o formaldeído nesta concentração não tem a função de alisante, apenas como conservante do produto, com o objetivo de preservá-lo de danos e/ou deteriorações causadas por microrganismos durante sua fabricação e estocagem (BRASIL, 2013).

Segundo a Associação Brasileira de Cosmetologia (2016), existem outras substâncias ativas menos agressivas e que representam menor risco a saúde com propriedades alisantes que são permitidas pela legislação, como: o ácido tioglicólico, hidróxido de sódio, hidróxido de potássio, hidróxido de cálcio, hidróxido de lítio e hidróxido de guanidina. Assim, não é preciso se submeter a tratamentos com formaldeído para ter cabelos lisos e nem aos riscos predispostos à saúde.

Destaca-se que o uso indevido da aplicação de formaldeído em procedimentos químicos como as escovas progressivas coloca em risco tanto os profissionais que realizam a aplicação dos produtos, como os clientes que ficam expostos à substância pelo contato com a pele e por inalação dos gases emitidos. Dentre esses riscos, estão: irritação, coceira, queimadura, descamação e vermelhidão do couro cabeludo, falta de ar, dor de cabeça, queda de cabelo, forte sensação de anestesia e necrose na pele superficial e, câncer principalmente nas vias aéreas superiores podendo ocasionar a morte (MACAGNAN; SARTORI; CASTRO, 
2017).

A fim de restringir o acesso da população ao formaldeído e coibir com o desvio de seu uso como alisante capilar, a Anvisa, por meio da RDC N 36, de 17 de junho de 2009, dispõe sobre a proibição da exposição, venda e entrega do formol ou formaldeído (solução a 37\%) para o consumo em drogaria, farmácia, armazém ou empório, supermercado, loja de conveniência e drugstore (BRASIL, 2009).

No entanto, a técnica de alisamento com formaldeído em altas concentrações, mesmo que seja ilegal, ainda é muito frequente nos salões de beleza, supondo, desta maneira, que os produtos são adulterados a critério do profissional de beleza de forma clandestina e em concentrações desconhecidas, pois não há produtos com formaldeído autorizados pela Anvisa com função de alisamento capilar (BELVISO, 2011; ABREU; AZEVEDO; FALCÃO, 2015).

Com relação à $\mathrm{RDC} \mathrm{N}^{\circ} 07$ de 10 de fevereiro de 2015 , que dispõe sobre os requisitos técnicos para a regularização de produtos de higiene pessoal, cosméticos e perfumes e outras providências, estabelece, nos Anexos V e VI desta resolução, o regulamento técnico sobre a

rotulagem geral obrigatória que traz informações indispensáveis que devem figurar nos rótulos concernentes a sua utilização, lembrando que, quando o produto não possuir embalagem secundária, toda informação deverá estar contida na embalagem primária, assim como toda a indicação necessária referente ao produto e especificações para alisantes. No caso dos alisantes capilares, as informações específicas são: não aplicar no couro cabeludo se estiver irritado ou com lesões e manter fora do alcance das crianças (BRASIL, 2015).

Diante do exposto, se viu a necessidade de realizar uma avaliação para averiguar a presença e concentração de formaldeído em amostra de alisantes capilares em salões de beleza no município de Itapaci-GO, verificando se os alisantes estão seguindo as normas exigidas pela legislação vigente, assim como a rotulagem destes produtos.

\section{METODOLOGIA}

Trata-se de uma pesquisa de campo/laboratorial de abordagem qualiquantitativa para analisar os rótulos e avaliar a presença formaldeído em amostras de alisantes capilares coletadas em salões de beleza no município de Itapaci-GO.

Primeiro, foi realizado um levantamento de dados na Vigilância Sanitária do município de Itapaci-GO, no mês de julho de 2018, para averiguar quantos salões (beleza/cabeleireiro) estavam em conformidade com o padrão mínimo exigido pela Anvisa e Visa Municipal, como licenciamento, estrutura física, abastecimento e uso de água, 
esgotamento sanitário, saúde ocupacional, procedimentos, produtos e equipamentos para funcionamento de estabelecimentos que realizam serviços de estética e embelezamento sem responsabilidade médica (BRASIL, 2009. Após essa coleta de dados, foi entregue aos proprietários um termo nos quais declararam consentimento em participar da pesquisa. Foi esclarecido pelas pesquisadoras os objetivos e a justificativa do estudo aos participantes, bem como a garantia do anonimato e que poderiam sair do estudo a qualquer momento sem penalidades.

Foram incluídos todos os estabelecimentos de beleza que trabalhavam com procedimentos químicos capilares, como: alisamento e escovas progressivas e, que possuíam cadastro atualizado no órgão vigente municipal. Foram excluídos salões que não realizam esses procedimentos capilares e que não estavam devidamente cadastrados no órgão municipal.

\subsection{ANÁLISE DE ROTULAGEM}

Foi realizado uma análise qualitativa dos rótulos das embalagens primárias dos alisantes capilares submetidos a avaliação por meio de uma investigação observacional crítica, seguindo os critérios estabelecidos pela RDC $\mathrm{N}^{\circ} 07$ de 10 de fevereiro de 2015, que define as normas de rotulagem obrigatória para produtos cosméticos. Os requisitos observados foram: nome do produto, marca, lote ou partida, modo de uso, advertências e restrições e rotulagem específica.

Essa análise foi realizada no dia em que as amostras de alisantes capilares foram coletas para a realização dos ensaios qualiquantitativos.

\subsection{COLETA DAS AMOSTRAS}

Para realizar a pesquisa qualiquantitativa de formaldeído em alisantes capilares, foram coletados no dia 06 de agosto de 2018, pelas pesquisadoras, entre $20 \mathrm{~mL}$ e $30 \mathrm{~mL}$ de cada amostra de alisante, as quais foram armazenadas em coletores universal que posteriormente foram revestidos com uma película filme de PVC afim de garantir a conservação do produto e evitar a volatilização do formaldeído (FIGURA 1).

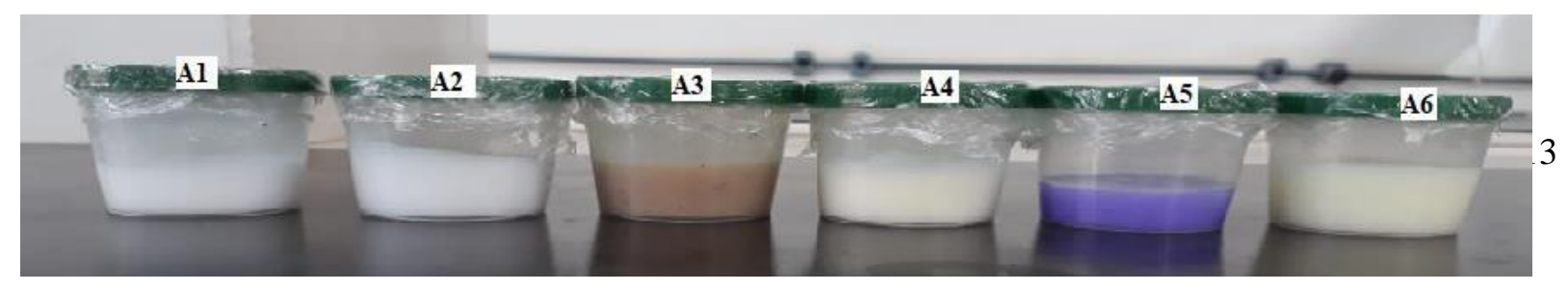


FIGURA 1: Armazenamento das amostras de alisantes capilares coletadas em salões de beleza no município de Itapaci-GO para realização da avaliação qualiquantitativa de formaldeído.

Destaca-se que essas amostras foram coletadas de frascos já abertos e em uso pelos proprietários.

Após a análise de rotulagem e coleta, as amostras de alisantes capilares foram encaminhadas e submetidas, no mesmo dia, à avaliação qualiquantitativa de formaldeído no Laboratório de Química I da Faculdade Evangélica de Ceres.

\subsection{AVALIAÇÃO QUALITATIVA:}

Para esta análise, inicialmente foi preparado o reagente de Schiff, em que foi dissolvido $1 \mathrm{~g}$ de fucsina básica e $1,8 \mathrm{~g}$ de metabissulfito de sódio em $100 \mathrm{~mL}$ de ácido clorídrico 0,15 M. A solução foi agitada manualmente em intervalos de dois minutos até atingir a coloração marrom-clara. Posteriormente, foram adicionados $500 \mathrm{mg}$ de carvão ativado, agitando novamente por dois minutos resultando em uma solução incolor. A solução foi filtrada com papel de filtro, lavando os resíduos com água destilada até que se completasse o volume de $100 \mathrm{~mL}$ original (BRASIL, 2000).

Posteriormente, foram pesados $2 \mathrm{~g}$ da amostra em um béquer de $10 \mathrm{~mL}$ e em seguida, adicionadas duas gotas de ácido sulfúrico $1 \mathrm{M}$ e $2 \mathrm{~mL}$ de reagente de Schiff que estava incolor no momento da utilização. A identificação do formaldeído em uma concentração superior a 0,01\% nas amostras foi comprovada pelo surgimento de uma coloração malva a roxa (BRASIL, 2007).

\subsection{AVALIAÇÃO QUANTITATIVA:}

Para as amostras que apresentaram- se positivas na avaliação qualitativa foi realizado o doseamento de formaldeído. Para a realização da avaliação, preparou-se as seguintes soluções/reagentes: reagente de acetilacetona, reagente sem acetilacetona, solução mãe de formaldeído padrão, solução diluída de formaldeído padrão, ensaio em branco, solução amostra e solução testemunha segundo Brasil (2007).

Determinação do título da solução mãe: Após o preparo das soluções, foi verificado a quantidade real de formaldeído presente na solução mãe de formaldeído padrão. Para isso, 
foram pipetadas $10 \mathrm{~mL}$ da solução mãe de formaldeído padrão, adicionando-se $25 \mathrm{~mL}$ de solução padrão de iodo $0,05 \mathrm{M}$ e $10 \mathrm{~mL}$ de solução de hidróxido de sódio $1 \mathrm{M}$. A solução foi deixada em repouso por durante cinco minutos e acidificada com $11 \mathrm{~mL}$ de ácido clorídrico 1 M. O iodo em excesso foi doseado com uma solução padrão de tiossulfato de sódio $0,1 \mathrm{M}$ em presença de goma de amido como indicador. A cada $\mathrm{mL}$ de solução de iodo 0,05 $\mathrm{M}$ consumida corresponde a $1,5 \mathrm{mg}$ de formaldeído. A determinação foi realizada em triplicata (BRASIL, 2007).

Curva padrão: Foram transferidos $5 \mathrm{~mL}$ da solução padrão diluída e $5 \mathrm{~mL}$ de reagente de acetilacetona para um erlenmeyer de $50 \mathrm{~mL}$ e em seguida, o volume foi completado com água até $30 \mathrm{~mL}$ e levado para banho-maria a $60{ }^{\circ} \mathrm{C}$ por dez minutos. Posteriormente, foi resfriado em banho de água fria por cinco minutos. Em seguida, a solução foi transferida para um filtro de decantação de $50 \mathrm{~mL}$ contendo $10 \mathrm{~mL}$ de 1-butanol. Logo, foi lavada com $5 \mathrm{~mL}$ de água destilada e a mistura foi agitada por trinta segundos, deixando-a decantar e filtrando a fase butanólica. O processo foi repetido com 10, 15, 20 e $25 \mathrm{ml}$ de solução padrão diluída. Posteriormente, determinou-se a absorbância (A1) a $410 \mathrm{~nm}$ do extrato da solução padrão diluída em relação ao 1-butanol. Em seguida, procedeu-se determinando a absorbância (A2) 
do extrato do ensaio em branco em relação a 1-butanol, também a $410 \mathrm{~nm}$. A curva padrão foi construída após a subtração do valor A1 - A2 (BRASIL, 2007).

Procedimento: Após o preparo das soluções: amostra, branco e testemunha foram levadas para o banho-maria a $60{ }^{\circ} \mathrm{C}$ por dez minutos e resfriadas em banho de água por dois minutos. Em seguida, as soluções (amostra, branco e testemunha) contidas nos erlenmeyers foram transferidas para um filtro de decantação de $50 \mathrm{~mL}$ contendo $10 \mathrm{~mL}$ de 1-butanol. Logo, foram lavadas com $5 \mathrm{~mL}$ de água destilada e as misturas foram agitadas por trinta segundos, deixando-as decantar e filtrando as fases butanólicas. Posteriormente, determinouse a absorbância (A1) a $410 \mathrm{~nm}$ do extrato da solução amostra em relação ao extrato da solução testemunha. Da mesma forma, foi determinado a absorbância (A2) do extrato do ensaio em branco em relação a 1- butanol, também a $410 \mathrm{~nm}$. Os resultados foram obtidos após a subtração do valor A1 - A2 (BRASIL, 2007).

Para determinar a quantidade de formaldeído nas amostras foi utilizado o cálculo:

$$
\mathrm{C}=\frac{\mathrm{c}}{10^{3} \times \mathrm{m}}
$$

Em que:

$\mathrm{C}=$ concentração (p/p) de formaldeído.

$\mathrm{c}=$ quantidade de formaldeído obtido a partir da curva analítica, em $\mu \mathrm{g}$.

$\mathrm{m}=$ massa da amostra em gramas.

Ressalta-se que o resultado final foi expresso em porcentagem comparando com a quantidade permitida pela legislação vigente (Resolução Colegiada $\mathrm{N}^{\circ} 15$, de 26 de março de 2013).

\section{RESULTADOS E DISCUSSÃO}

Os salões de beleza são considerados estabelecimentos que prestam serviços de forma direta ou por meio de parceiros, utilizando uma estrutura especializada para a realização de atividades relacionadas a estética e embelezamento, venda de artigos, cosméticos, acessórios e/ou qualquer outro produto que vise a boa imagem e bem-estar dos clientes (ABNT; SEBRAE, 2016). Vale ressaltar que, todos os salões de beleza devem possuir o alvará de licença sanitária, que é um documento expedido pelo órgão sanitário municipal que libere o funcionamento dos estabelecimentos que exerçam atividades sob regime da vigilância sanitária local (BRASIL, 2009). 
Logo, por meio do levantamento realizado no mês de julho na Vigilância Sanitária do município de Itapaci-GO, haviam 21 salões com cadastros atualizados e que 52,38 \% (11/21) realizam procedimentos capilares, dos quais 54,54 \% (6/11) aceitaram participar do estudo, assinando o termo de consentimento para participar da pesquisa.

É importante destacar que foi usado como critério de seleção apenas salões de beleza que estivessem em situação regular junto à Vigilância Sanitária local, pois, como descrito por Britto (2004), técnicas realizadas em salões de beleza podem colaborar, de modo considerável, no processo saúde-doença, ou seja, salões de beleza que não se adequam as exigências da vigilância local oferecem maior riscos/danos a aparência e/ou saúde do cliente.

Os alisantes capilares são armazenados em recipientes cuja principal função é proteger o produto e contribuir com o seu prazo de validade. Normalmente, esses recipientes são adquiridos dentro de caixas. Diante disso, Brasil (2015) define que embalagem primária é todo envoltório que mantenha contato direto com o produto, já embalagem secundária é o recipiente que contenha a (s) embalagem (ens) primária (as).

$\mathrm{Na}$ análise qualitativa da rotulagem, $100 \%$ dos rótulos das embalagens primárias dos alisantes capilares analisados estavam em conformidade com os requisitos obrigatórios para embalagens primárias descrito na RDC No 07 de 10 de fevereiro de 2015 (BRASIL, 2015), que são: nome do produto, marca, lote/partida, modo de uso, advertências e restrições e rotulagem específica. Em contrapartida, na análise desenvolvida por Silvestre et al. (2017), todos os 13 rótulos das embalagens de alisantes capilares analisadas apresentaram irregularidades tanto na embalagem primária quanto secundária. Quanto a embalagem primária, as irregularidades apresentadas foram por ausência de lote, advertências/restrições e rotulagem específica.

As informações contidas nos rótulos dos produtos de higiene pessoal, cosméticos e perfumes, como os alisantes capilares, são de extrema importância já que têm por objetivo estabelecer aos consumidores/usuários informações indispensáveis referentes a utilização do produto, assim como toda indicação necessária pertencente ao mesmo, possibilitando a identificação de possíveis substâncias que lhes causem alergias, principalmente relacionadas a fragrância do produto (RITO et al., 2014).

Importante ressaltar que antes de se adquirir um produto para realização de alisamento capilar em salão de beleza, o cabeleireiro deve, antes de tudo, verificar se o produto tem registro na Anvisa, devendo recusar qualquer tipo de formulação caseira, pois não apresenta segurança quanto a sua preparação e ingredientes. Além disso, é de extrema importância 
verificar todas as informações quanto à modo de uso e advertências específicas, oferecendo produtos de qualidade e seguros a seus clientes (BRASIL, 2016).

Tão importante quanto as demais observações, cabe também verificar a data de validade, pois produtos vencidos podem ter seu efeito desejado alterado e são mais propícios a causar reações adversas devido à instabilidade dos componentes da formulação (SVERSUT et al., 2017).

Quanto à avaliação qualitativa para verificar a presença de formaldeído, das 6 amostras analisadas, todas foram positivas apresentando uma coloração malva a roxo escuro, indicando a presença de formaldeído (acima de 0,01\%) (FIGURA 2).

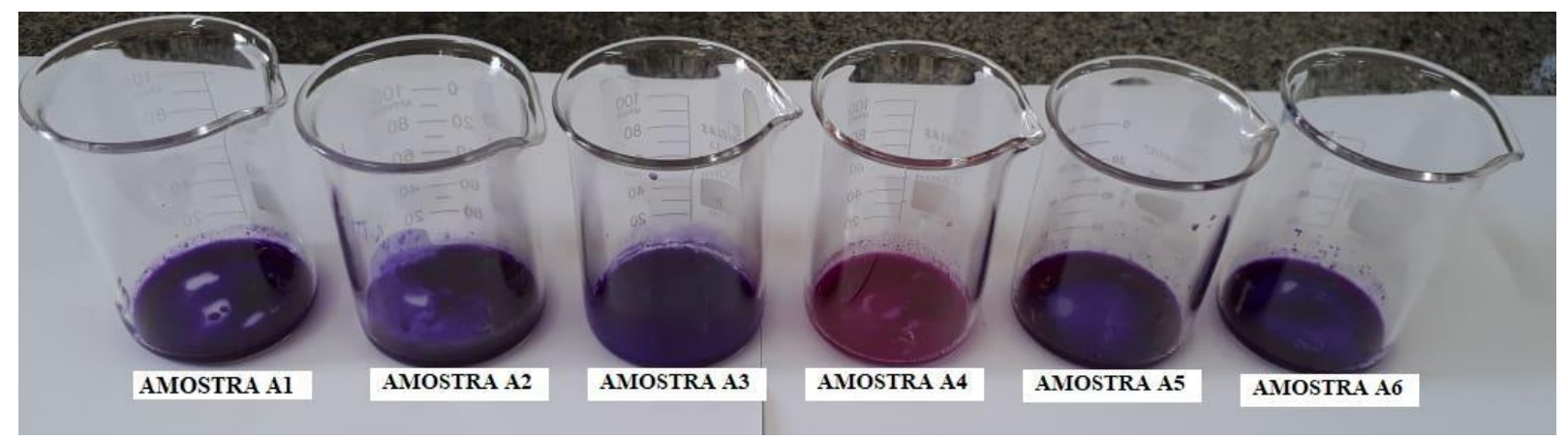

FIGURA 2. Reação positiva para presença de formaldeído (acima de 0,01\%) em amostras de alisantes capilares coletadas em salões de beleza no município de Itapaci-GO.

Conforme o descrito no Guia de Controle de Qualidade de Produtos Cosméticos da Anvisa (BRASIL, 2007), em meio sulfúrico e na presença do reagente de Schiff, o formaldeído livre e/ou combinado passa a apresentar uma coloração malva a roxa, indicando presença da substância superior a 0,01 \%. Nota-se, conforme FIGURA 2, que as amostras A1, A2, A3, A5 e A6 apresentaram uma coloração roxo intenso, enquanto a amostra A4 apresenta coloração próxima de malva.

No estudo desenvolvido por Ferreira (2015), foi possível verificar que as 17 amostras de progressivas e selantes capilares analisadas na avaliação semi-quantitativa também se mostraram positivas para presença de formaldeído. Em outro estudo, no qual foi realizado uma avaliação qualitativa de formaldeído em alisantes capilares obtidas em salões de beleza em Araraquara-SP, desenvolvido de Silvestre et al. (2017), todas as 13 amostras avaliadas se demonstraram positivas para a presença de formaldeído, ambos utilizando a mesma metodologia do presente trabalho. Comparando-se assim o padrão de resultados dos estudos analisados juntamente com os resultados obtidos na pesquisa, sugere-se que o formaldeído é uma substância altamente empregada em formulações de alisantes capilares, ressaltando também que foi observado na análise de rotulagem a presença de formaldeído e $100 \%$ das 
amostras não possuíam a substância descrita como componente do produto, podendo insinuar que o formaldeído é utilizado de forma irregular, fora dos parâmetros exigidos pela lei vigente.

Posteriormente à avaliação qualitativa, as 6 amostras que acusaram a presença de formaldeído foram submetidas a avaliação quantitativa para doseamento global de formaldeído por colorimetria com acetilacetona. Neste método de avaliação, o formaldeído reage com a acetilacetona em presença de acetato de amônio formando o composto 3,5diacetil-1,4-dihidrolutidina, que foi extraído com 1-butanol e a absorbância do extrato determinada a $410 \mathrm{~nm}$ em espectrofotômetro digital (modelo 850MI).

Para se obter a quantidade de formaldeído presente em cada amostra, primeiro foi construída uma curva padrão a partir de solução diluída de formaldeído padrão com cinco pontos.

A curva de calibração atingida apontou equação da reta $A=0,0445 C-0,0737$, com coeficiente de determinação $\left(R^{2}\right)$ igual a 0,9953 , onde A é igual a absorbância e C a concentração de solução diluída de formaldeído padrão.

Com a realização da avaliação quantitativa, foi possível observar que 83,33\% (5/6) das amostras apresentaram formaldeído em concentrações acima do valor máximo permitido $(0,2$ $\%)$ e apenas a amostra A4 apresentou valor dentro do permitido (TABELA 1). É válido ressaltar que a amostra A4 manifestou coloração mais clara que as demais em contato com o reagente de Schiff em meio sulfúrico na avaliação qualitativa.

\begin{tabular}{c|c}
\hline AMOSTRAS & TEOR DE FORMALDEÍDO (\%) \\
\hline A1 & $1,17 \pm 0,0097 \%$ \\
A2 & $1,21 \pm 0,0331 \%$ \\
A3 & $0,47 \pm 0,0163 \%$ \\
A4 & $0,16 \pm 0,0021 \%$ \\
A5 & $0,59 \pm 0,0112 \%$ \\
A6 & $1,34 \pm 0,0298 \%$ \\
\hline
\end{tabular}

Tabela 1. Percentual de formaldeído encontrado nas amostras de alisante capilar coletadas nos salões de beleza no município de Itapaci-GO.

Através dos resultados encontrados, nota-se que o uso irregular de formaldeído em formulações cosméticas para alisamento capilar ainda persiste mesmo diante da legislação vigente $\mathrm{RDC}^{\circ} 15$ de 26 de março de 2013 (BRASIL, 2013), que limita o uso dessa substância $(0,2 \%)$. 
Estudos realizados por Crippa, Teixeira e Rebello (2015) e Moro et. al. (2015), corroboram com o presente estudo, pois as formulações de alisantes capilares analisadas apresentaram teores de formaldeído acima do permitido pela legislação, demonstrando porcentagens exorbitantes, chegando a encontrar a substância em concentração de 18,5 \% .

Também exemplo de irregularidade como este foi registrado no mês de março de 2018 no Estado de Pernambuco, em que quatro alisantes de cabelo que estavam sendo comercializados no mercado foram notificados e não podem ser distribuídos, divulgados, comercializados e nem utilizados devido a identificação da presença de formaldeído em níveis acima do limite tolerado pela legislação vigente. Segundo as análises de formaldeído feitas pelo Laboratório Central de Saúde Pública de Pernambuco, os produtos apresentavam concentração maior do que $0,2 \%$ e irregularidades nos rótulos (BRASIL, 2018).

Cabe ressaltar que no presente estudo, nenhuma das amostras analisadas apresentavam no rótulo a presença de formaldeído em sua composição. Isso demonstra que, caso não tenha sido adulterado pelo próprio profissional cabeleireiro, os produtos analisados já apresentavam formaldeído desde sua composição original de fábrica, demonstrando que a fiscalização deve ser mais rigorosa desde a etapa de produção até a venda do produto.

Quanto ao formaldeído adicionado em alisantes capilares, pronto para uso, em salões de beleza ou qualquer outro estabelecimento, além de acarretar riscos à saúde, contraria o disposto na regulamentação de produtos de higiene pessoal, cosméticos e perfumes e configura em infração sanitária federal (Lei no 6.437/1977) e crime hediondo de acordo com o Código Penal (BRASIL, 2009).

De acordo com Silva et. al. (2017), os principais sintomas relacionados a alta concentração de formaldeído em alisantes capilares são: alergias, queimaduras e queda dos cabelos. Sintomas como, coriza, coceira, falta de ar, tosse e dor de cabeça são ocasionadas pela exposição aguda por contato com pele e/ou mucosas e absorção respiratória e/ou gastrointestinal. Câncer na nasofaringe e leucemias são ocasionadas pela exposição crônica do produto, e em concentrações entre 50 - 100 ppm pode levar à morte.

Ressalta-se que todos os proprietários que aceitaram participar do estudo foram informados dos resultados encontrados.

\section{CONCLUSÃO}

Através da realização da pesquisa, foi possível observar que todos os rótulos das embalagens primárias dos alisantes capilares analisados estavam em conformidade com a 
RDC $\mathrm{N}^{\circ}$ 7, de 10 de fevereiro de 2015. Na avaliação qualitativa, todas as amostras mostraram-se positivas para a presença de formaldeído acima de $0,01 \%$ e na avaliação quantitativa, $83,33 \%(5 / 6)$ das amostras avaliadas apresentaram formaldeído acima do permitido pela Anvisa (0,2\%).

Diante disso, percebe-se a extrema necessidade de maior fiscalização e medidas mais rígidas durante a fabricação do alisante, como também maior promoção de campanhas por meio da Vigilância Sanitária local para conscientizar tanto os proprietários dos salões como os consumidores a respeito dos riscos/ danos à saúde por conta do uso indevido de formaldeído, principalmente associado a práticas ilegais como a adição da substância ao produto já acabado.

\section{REFERÊNCIAS}

ABIHPEC. Associação Brasileira da Indústria e Higiene Pessoal, Perfumaria e Cosméticos. Mercado brasileiro de HPPC: quarta posição mundial com sensação de terceira. São Paulo, 2017. Disponível em: <https://abihpec.org.br/2017/02/mercado-brasileiro-de-hppc-quartaposicao-mundial-com-sensacao-de-terceira/> . Acesso em: 01 de abril de 2018.

ABREU, V. M.; AZEVEDO, M. G. B.; FALCÃO, J. S. A. Cosmetovigilância em alisantes capilares: Determinação do teor de formaldeído por espectrofotometria e avaliação do rótulo. Journal of Basic and Applied Pharmaceutical Sciencies, v. 36, n. 1, 2015. Disponível em: <http://seer.fcfar.unesp.br/rcfba/index.php/rcfba/article/download/207/115>. Acesso em: 25 de março de 2018.

AGE DO BRASIL. Indústria: Quais os produtos cosméticos mais usados no Brasil? 2017. Disponível em: <http://agedobrasil.com.br/industria-quais-os-produtos-cosmeticos-maisusados-no-brasil/>. Acesso em: 01 de maio de 2018.

ASSOCIAÇÃO BRASILEIRA DE COSMETOLOGIA. Anvisa dá orientação sobre alisantes. 2016. Disponível em: <http://www.abc-cosmetologia.org.br/anvisa-da-orientacoessobre-alisantes/>. Acesso em: 24 de maio de 2018.

ABNT, Associação brasileira de normas técnicas; SEBRAE, Serviço brasileiro de apoio às micro e pequenas empresas. Salão de Beleza: Guia de Boas Práticas - Rio de Janeiro: ABNT; Sebrae, 2016. Disponível em

<http://abnt.org.br/paginampe/biblioteca/files/upload/anexos/pdf/211055df2da423ea7708506a b7a3be0c.pdf>. Acesso em: 22 de novembro de 2018. 
BELVISO, T. I. Os perigos do uso inadequado do formol na estética capilar. Revista Intertox de Toxicologia, Risco Ambiental e Sociedade, v. 4, n. 1, 2015. Disponível em:<http://www.revistarevinter.com.br/autores/index.php/toxicologia/article/download/68/28 2>. Acesso em: 25 de abril de 2018.

BRASIL. Agência de Vigilância Sanitária. Orientações sobre alisantes. 2016. Disponível em: < http://portal.anvisa.gov.br/alisantes>. Acesso em: 23 de maio de 2018.

BRASIL. Agência Nacional de Vigilância Sanitária. Formol leva quatro alisantes de cabelo à proibição. 2018. Disponível em: <http://portal.anvisa.gov.br/rss//asset_publisher/Zk4q6UQCj9Pn/content/id/4181968>. Acesso em: 06 de abril de 2018.

BRASIL. Agência Nacional de Vigilância Sanitária. Guia de Controle de Qualidade de Cosméticos. Uma Abordagem sobre os Ensaios Físicos e Químico. Editora Anvisa. Brasília, 2007. Disponível em: <https://www.crq4.org.br/downloads/guia_cosmetico.pdf>. Acesso em: 25 de abril de 2018.

BRASIL. Farmacopeia Brasileira IV edição. Texto que substituiu o publicado, anteriormente, na parte I. 2000. Disponível em: < http://www.anvisa.gov.br/hotsite/farmacopeiabrasileira/publicacoes/4_edicao/parte2/substitui coes2.pdf >. Acesso em: 21 de agosto de 2018.

BRASIL. Agência Nacional de Vigilância Sanitária. Referência técnica para o funcionamento dos serviços de estética e embelezamento sem responsabilidade médica. 2009. Disponível em: $<$ http://portal.anvisa.gov.br/documents/33856/2054354/Refer\%C3\%AAncia+t\%C3\%A9cnica +para+o+funcionamento+dos+servi\%C3\%A7os+de+est $\% \mathrm{C} 3 \% \mathrm{~A} 9$ tica+e+embelezamento+se $\mathrm{m}+$ responsabilidade $+\mathrm{m} \% \mathrm{C} 3 \%$ A9dica/e37a023b-91c0-4f07-993a-393d041156ab>. Acesso em: 22 de novembro de 2018.

BRASIL. Ministério da Saúde. Agência Nacional de Vigilância Sanitária. Resolução de Diretoria Colegiada $n^{\circ}$ 36, de 17 de junho de 2009. Dispõe sobre a proibida a exposição, a venda e a entrega ao consumo de formol ou de formaldeído (solução a 37\%) em drogaria, farmácia, supermercado, armazém e empório, loja de conveniência e drugstore. 2009. Disponível em: <http://portal.anvisa.gov.br/documents/10181/2718376/RDC_36_2009_.pdf/e6695b45-82294bf3-bc38-4674e0309aa5>. Acesso em: 21 de abril de 2018.

BRASIL. Ministério da Saúde. Agência Nacional de Vigilância Sanitária. Resolução de Diretoria Colegiada $\mathbf{N}^{\circ}$ 15, de 26 de março de 2013. Aprova o Regulamento Técnico sobre lista de substâncias de uso cosmético: acetato de chumbo, pirogalol, formaldeído e paraformaldeído. 2013. Disponível em: 
<http://bvsms.saude.gov.br/bvs/saudelegis/anvisa/2013/rdc0015_26_03_2013.pdf>. Acesso em: 06 de abril de 2018.

BRASIL. Ministério da Saúde. Agência Nacional de Vigilância Sanitária. Resolução de Diretoria Colegiada $n^{\circ}$, de 10 de fevereiro de 2015. Dispõe sobre os requisitos técnicos para a regularização de produtos de higiene pessoal, cosméticos e perfumes. 2015. Disponível em: <http://portal.anvisa.gov.br/documents/10181/2867685/RDC_07_2015_.pdf/c2a1078c46cf-4c4b-888a-092f3058a7c7>. Acesso em: 01 de abril de 2018.

BRITTO, M. D. G. M. Obrigatoriedade da licença para funcionamento em salões de beleza no distrito federal. Revista de Direito Sanitário, v. 5, n. 3, p. 114-128, 2004. Disponível em: < http://www.journals.usp.br/rdisan/article/view/79841/83799>. Acesso em: 27 de setembro de 2018.

CRIPPA, V.; TEIXEIRA, L.; REBELLO, L. Análise quali-quantitativa de formaldeído em amostras de produtos destinados ao alisamento capilar utilizados em salões de beleza no município de Linhares, ES-Brasil. Infarma- Ciências Farmacêuticas, v. 27, n. 1, p 22-27, 2015. Disponível em: < http://oaji.net/articles/2016/3425-1469795170.pdf>. Acesso em: 15 de março de 2018.

FERREIRA, L. A. et al. Substâncias ativas do alisamento capilar e seus mecanismos de ação. Electronic Journal of Pharmacy, v. XIII, n. 2, p. 56-63, 2016. Disponível em: <https://revistas.ufg.br/REF/index>. Acesso em: 10 de março de 2018.

FERREIRA, V. T. Avaliação semi- quantitativa da concentração de formaldeído em formulações cosméticas de alisamento progressivo e selantes capilares. Monografia [Graduação em Farmácia] Universidade de Brasília, Ceilândia, 2015. Disponível em: <http://bdm.unb.br/bitstream/10483/10637/1/2015_VeridianaTorresFerreira.pdf >. Acesso em: 25 de abril de 2018.

IONTA, L. M. P.; SILVA, J. O. Efeitos Tóxicos do Formaldeído em Escova Progressiva. In: $10^{\circ}$ MOSTRA ACADÊMICA UNIMEP, CONGRESSO DE PÓS-GRADUAÇÃO. Anais... Piracicaba, São Paulo, 2012. Disponível em:

<http://www.unimep.br/phpg/mostraacademica/anais/10mostra/5/483.pdf >. Acesso em: 21 de abril de 2018.

MACAGNAN, K. K.; SARTORI, M. R. K.; CASTRO, F. G. Sinais e sintomas da toxidade do formaldeído em usuários de produtos alisantes capilares. Cadernos da Escola de Saúde, v. 2, n. 4, 2017. Disponível em:

<http://portaldeperiodicos.unibrasil.com.br/index.php/cadernossaude/article/download/2304/1 877>. Acesso em: 25 de abril de 2018. 
MORO, J. et al. Avaliação qualitativa e quantitativa de formaldeído em produtos cosméticos para alisamento capilar. Revista de Ciências Farmacêuticas Básica e Aplicada, v. 36, n. 4, 2015. Disponível em: <

https://web.a.ebscohost.com/abstract?direct=true \&profile=ehost\&scope=site \&authtype $=$ crawl er\&jrnl=18084532\&AN=132005749\&h=BcNTI0OJuv65dEmW6CavI5Gs Yh51f8Fq9qDIYij MXQSzWNZH0agwfsCwYkjKkMq6qs9gF4aU1avbBD71ehng3g\%3d\%3d\&crl=c\&resultNs= AdminWebAuth\&resultLocal=ErrCrlNotAuth\&crlhashurl=login.aspx\%3fdirect $\% 3 \mathrm{dtrue} \% 26 \mathrm{p}$ rofile $\% 3$ dehost $\% 26$ scope $\% 3 \mathrm{dsite} \% 26$ authtype $\% 3 \mathrm{dcrawler} \% 26 \mathrm{jrnl} \% 3 \mathrm{~d} 18084532 \% 26 \mathrm{AN} \% 3 \mathrm{~d}$ 132005749>. Acesso em: 16 de agosto de 2018.

RITO, P. N. et al. Perfil dos desvios de rotulagem de produtos cosméticos analisados no Instituto Nacional de Controle de Qualidade em Saúde entre 2005 e 2009. Revista Visa em Debate, Sociedade e Ciência Tecnologia, Rio de Janeiro - RJ, v. 2, p.44-50, 2014.

Disponível em: <

https://www.arca.fiocruz.br/bitstream/icict/8574/2/Vig\%20Sanit\%20Debate_2_44-50.pdf>. Acesso em: 30 de out de 2018.

SILVA, J. V. M. A. et al. Risco do uso do formol na estética capilar riesgo del uso del formol en la estética capilar. Medicina Legal de Costa Rica, v. 34, n. 2, p. 32-42, 2017. Disponível em:

<http://www.scielo.sa.cr/scielo.php?script=sci_arttext\&pid=S140900152017000200032>. Acesso em: 29 de setembro de 2018.

SILVESTRE, A. L. P. et al. Análise qualitativa do formaldeído em amostras de alisantes capilares obtidas em salões de beleza de Araraquara-SP. Journal of Basic and Applied Pharmaceutical Sciencies, v. 38, 2017. Disponível em:

$<$ http://seer.fcfar.unesp.br/rcfba/index.php/rcfba/article/download/719/439>. Acesso em: 05 de março de 2018.

SVERSUT, R. A. et al. Quality control of capillary straighteners containing ammonium thioglycolate. Revista Colombiana de Ciências Químico-Farmacêuticas, v. 46, n. 3, p. 303-318, 2017. Disponível em: <http://www.scielo.org.co/scielo.php?pid=S0034$74182017000300303 \&$ script=sci_arttext\&tlng=pt $>$. Acesso em: 30 de set de 2018. 